\title{
Exílio Massivo, Inclusão e Exclusão Política no Século XX*
}

Luis Roniger

\section{INTRODUÇÃO}

T a América Latina do século XX, tem início um processo de massi1 ficação do exílio. Até então, costumava-se usar o desterro como mecanismo de ostracismo reservado normalmente àqueles que pertenciam às classes privilegiadas e a suas redes de apoio. Tanto para esses quanto para os que os forçavam a tomar o caminho do desterro o exílio funcionou como mecanismo de exclusão política paralelo e preferível ao "encarceramento" ou ao "sepultamento" (Luna, 1995:202; Bonilla, 1989:1-2 apud Barahona, 2005:101), sendo esse último geralmente o destino de opositores desgraçados oriundos das classes populares. A partir do século $X X$, o exílio político passa a ser usado cada vez mais frequentemente contra ativistas políticos e sindicais, intelectuais, estudantes e profissionais de todas as classes sociais, cujo único delito haviam sido a participação e a mobilização política contra um governo ou regime eventual.

A massificação do exílio ocorreu paralelamente à natureza cambiante dos conflitos políticos e sociais da região. Os países latino-americanos

\footnotetext{
* Este artigo foi elaborado durante uma residência de investigação no Instituto de Altos Estudos (IAS), da Universidade Hebraica de Jerusalém, entre fevereiro e agosto de 2009. O autor agradece a assistência de Orly Haimovich na preparação do trabalho e a Gabriel Mordoch a versão portuguesa do texto, redigido originalmente, em castelhano, com o título "Exilio Masivo, Inclusión y Exclusión Política en el Siglo XX".

DADOS - Revista de Ciências Sociais, Rio de Janeiro, vol. 53, n- 1, 2010, pp. 91 a 123.
} 
atravessaram - em ritmos diferentes, porém de maneira quase homogênea - processos de crescimento populacional, mobilidade territorial, modernização socioeconômica e crescente urbanização. Em cada um dos países, o ritmo desigual das transformações criou acentuadas assimetrias internas. Apesar das diferenças e das especificidades, durante o século $X X$ a região foi cenário de profundas transformações: emergência de centros dinâmicos de desenvolvimento nos entornos urbanos, emergência de economias extrativas e de enclaves econômicos ligados ao capital internacional, pressões para a ampliação da participação política e a democratização das sociedades, defasagem da vida tradicional e cristalização de estilos de vida modernos, e diversificação do âmbito religioso, entre outras.

Neste artigo, é analisado como esses processos afetaram o caráter do exílio político, principal mecanismo de exclusão institucional empregado pelos estados ibero-americanos desde seu estabelecimento no século XIX. A análise indica que houve várias fases de estruturação do exílio e se concentra no estudo da transição do uso restritivo desse mecanismo a seu emprego massivo a partir do fim do século XIX e início do século XX. A tese sugerida neste artigo é a de que um número cada vez maior de exilados de diferentes classes sociais se veem afetados por sua participação no âmbito político e nas esferas públicas, criando um fenômeno de ampla transcendência que viria a transformar a funcionalidade do exílio e sua função para os estados ibero-americanos. A ampliação da exclusão institucional deu lugar a uma dinâmica de dispersão dos exilados, o que lhes permitiu gerar amplas redes de solidariedade e centralizar cada vez mais a atenção da esfera pública internacional no exílio como reflexo das políticas de exclusão e de repressão empregadas nos países expulsores. A crescente conscientização produz então uma radical transformação na estrutura, no impacto e na funcionalidade do exílio político nos estados ibero-americanos.

\section{USO E ABUSO DO EXÍLIO COMO MECANISMO DE EXCLUSÃO POLÍTICA}

O exílio político tem sido um dos mecanismos centrais de dominação e de exclusão forjados pelas elites políticas latino-americanas a fim de se manterem no poder. Sob distintas formas, definições e módulos operativos, desde o deslocamento forçado e o desterro à expatriação e à migração voluntária (porém precipitada), o exílio tem desempenhado papel vital na configuração de moldes e de estilos da política latino-americana. 
Os estudos históricos, sociológicos e políticos têm reconhecido prontamente a centralidade do exílio político nesse contexto (San Cristóval, 1941; Luna, 1962; Rodríguez Plata, 1976; Zúñiga, 1982; Yundt, 1988; Lynch, 1989; Johnson, 1992; Katra, 1996; Loveman e Lira, 1999). Historicamente, as raízes do fenômeno são anteriores ao estabelecimento dos estados independentes, remontando ao período colonial, quando as autoridades se valeram da transferência e da expulsão de indivíduos como parte de suas políticas de povoamento e defesa e, de forma paralela, como mecanismo de controle social, dirigido a inadaptados sociais, marginais, criminosos ou rebeldes (Scardaville, 1977:304-350; Descalzi, 1978; Herzog, 1995).

A desintegração do império espanhol nas Américas e a subsequente disputa desenfreada pelo poder geraram situações propícias à generalização do uso do deslocamento forçado como mecanismo de regulação empregado com maior frequência. Situações de luta iminente entre elites suscitaram com frequência o dilema entre aniquilar o oponente, com o consequente perigo de iniciar um círculo vicioso de retaliações, ou mobilizar forças das camadas sociais inferiores a fim de vencer o oponente. A primeira alternativa implicava o perigo de gerar uma situação conhecida nas ciências políticas como "soma-zero", em que há a percepção de que o lucro de uma das partes envolvidas significa o prejuízo de outras partes, o que eventualmente geraria conflitos crescentes, capazes de ferir letalmente e de maneira completa uma camada social privilegiada. A segunda opção não implicava um perigo menor aos olhos das elites: a abertura do jogo político republicano a estratos sociais marginalizados, cuja presença poderia acarretar uma "guerra de castas" ou um conflito étnico, o que igualmente ameaçaria a hegemonia da classe governante e a estrutura do poder.

As elites pressentiam, por meio do inato sentido de sobrevivência e de ansiada conservação de sua hegemonia política, que a execução do líder de uma facção inimiga poderia dar início a um ciclo de retaliação capaz de gerar as condições necessárias à eliminação da classe dominante ou implicar a abertura e o incremento da luta política até o ponto de incluir as camadas sociais inferiores, o que seria igualmente negativo para a intenção de conservar sua posição na pirâmide social. Mediante tal dilema, o uso do exílio político fazia sentido, uma vez que se apresentava como solução intermediária e respeitava a condição de classe dos afetados, deslocando-os meramente do solo da pátria para outros territórios (Roniger e Sznajder, 2008). 
Por outro lado, o desterro constituía uma pena significativa, já que, em virtude das condições de comunicação da época, implicava a ruptura das redes sociais, a perda de protagonismo político e muitas vezes a perda de fontes de sustento que mantivessem o nível de vida a que o desterrado estava acostumado no habitat anterior.

É assim que o desterro se transforma em uma fórmula política que permite manter o controle da esfera pública sem incorrer nos eventuais custos de um crescente ciclo de violência irredentista. O exílio adquire, desse modo, seu perfil político como mecanismo de exclusão institucionalizada, ao lado da prisão, da pena de morte e de outras medidas de exceção e de emergência usadas exaustivamente desde então (Loveman, 1993). Entre os mecanismos de exclusão institucionalizada mencionados por Félix Luna (1995) e Emma Bonilla (1989), o exílio político foi a opção mais profusamente usada, em especial para com aqueles que foram expulsos de posições de poder. Conscientes de sua própria debilidade numérica, bem como da fragilidade no poder, as elites governantes viram, no exílio político, um mecanismo particularmente favorável à manutenção da estrutura hierárquica da esfera política nas nações ibero-americanas recém-independentes.

Uma vez deslocados do território original, os exilados passaram a participar de um jogo transnacional em que seus próprios projetos de retorno interagiam com os interesses do governo do país receptor em lograr uma hegemonia regional pelo uso das redes de exilados, e isso diante de uma das motivações daqueles que provocavam o exílio, ou seja, a intenção de manter a oposição afastada do território nacional.

O exílio se configura como uma estrutura tríplice, na qual elites de países limítrofes protagonizam um papel destacado na política e nas esferas públicas dos países próximos. A ligeira cristalização de estados autônomos no âmbito hispano-falante exacerbou tal dinâmica no que tange a demandas e a disputas territoriais por parte das elites de diferentes cidades e regiões americanas (Sznajder e Roniger, 2009:73-90).

As classes políticas intervieram, portanto, de acordo com seus próprios interesses, na configuração das facções políticas dos países vizinhos. Quando a facção que um governo apoiava em um país vizinho era derrotada, frequentemente os atores políticos vencidos encontravam asilo no território limítrofe, recebendo inclusive apoio do governo local a seus planos de retorno. Cabe dizer que, apesar da derrota, a política regional continuou desempenhando um papel central, dado que 
elites governantes do país anfitrião atuaram dessa maneira a fim de recuperar o controle da cena política vizinha ou, pelo menos, exercer alguma influência diante do fortalecimento de aliados políticos em potencial. Mesmo quando a facção derrotada era contrária à política forjada pelo governo anfitrião, este poderia acolher os desterrados com a finalidade de controlar sua liberdade de ação, reduzindo as possibilidades de conspiração dos exilados contra um governo aliado no país vizinho. Em todos os casos, os indivíduos e as comunidades de exilados desempenhavam um papel importante nessa estrutura de três níveis, protagonizando um papel seja dentro dos planos de hegemonia regional dos países de acolhimento, seja quanto às opções abertas às elites no poder em seu país de origem (ver Figura 1).

A presença dos exilados foi então tolerada e até mesmo promovida como ferramenta política a ser utilizada pelo país anfitrião em relação ao cenário político do país de origem dos desterrados. Essa atitude se refletiu não somente no país de origem dos exilados, mas também colaborou para a definição de regras de pertencimento à comunidade política de acolhimento. Por exemplo, os exilados políticos argentinos que

Figura 1

Formato prévio do exílio político ibero-americano

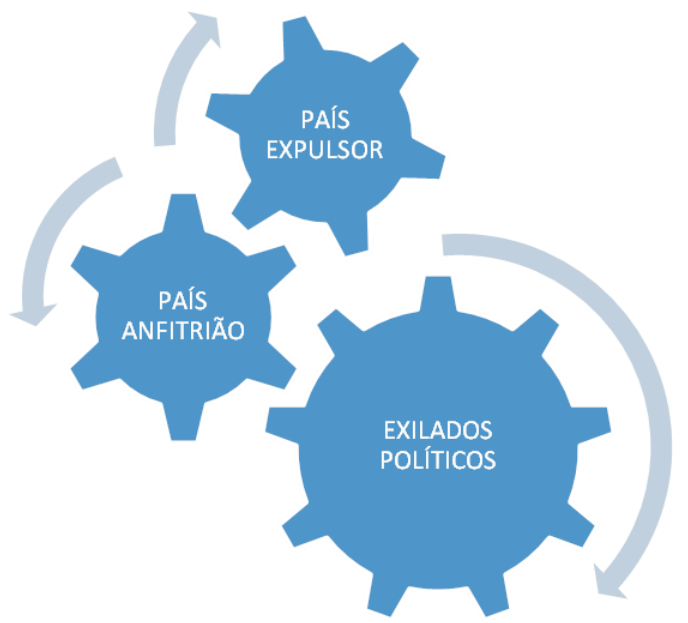

País expulsor

Exclusão da esfera pública

Expulsão territorial

Fuga para o exterior

Relegação interna

"Insílio", ou exílio interior
Exilados políticos

Motivações

Vias de saída

Deslocamento

Atividade política exterior

Exílio em série
País anfitrião

Políticas de asilo

Módulo de recepção

Mecanismos de apoio

Limitações

Uso político dos exilados 
se estabeleceram no Chile sob o regime conservador eram bem-vindos desde que não interferissem na política interna ou desde que apoiassem os governantes no poder. Quando assumiram posições contrárias ao governo, os exilados foram expulsos do país (Halperín Donghi, 1980:500). O exílio se converte assim em um mecanismo central na vida política, inerente às pautas da configuração da política moderna dos regimes governantes na América Latina. Na expressão de Hirschman (1970), a política de exit [deslocamento] passou a vigorar sobre uma política de voice [articulação expressiva]. Quando a política chegou a níveis mais altos de consolidação, o exílio já havia sido internalizado pela cultura política como mecanismo central de exclusão institucional que prevalecia sobre formas mais abertas e pluralistas de fazer política (Roniger e Green, 2007).

Um dos indicadores mais claros da internalização do exílio na cultura política é a abordagem regional do tema do asilo em tratados e convenções que os países ibero-americanos entabularam já a partir das décadas de 1960 e 1970, tornando-se pioneiros nesse âmbito. Entre os antecedentes, devemos mencionar que, no Ocidente, a Revolução Francesa constituiu um divisor de águas. Ao proclamar "os direitos do homem e do cidadão", reconheceu a resistência à opressão enquanto direito natural e perene, assentando assim, tacitamente, as bases para o reconhecimento da perseguição política como uma figura legal, base do conceito moderno de asilo político. No século XIX, a figura do asilo político se converteu rapidamente em um foco de interpretação jurídica e de legislação (Luna, 1962:20-1) ${ }^{1}$.

Na América Latina, houve prontas tentativas de enfrentar o problema do asilo político em face de um pano de fundo contraditório. Por um lado, o movimento de exilados gerava instabilidade. Por outro, os fatores de poder podiam utilizar os exilados para acossar seus inimigos políticos nos países vizinhos. Mesmo quando os governos podiam ter se mostrado contrários à concessão de asilo aos "alvoroçadores" dos países vizinhos, não puderam ignorar que, com o tempo, eles mesmos talvez precisassem recorrer a esse mecanismo caso fossem derrocados do poder por um golpe de Estado. Consequentemente, essa questão se converteu em um tema muito debatido nas negociações e nas reuniões sobre o asilo diplomático, tornando a América Latina uma região pioneira nesse assunto (Franco et alii, 2001; Esponda Fernández, 2007). 
Em 1867, os representantes diplomáticos dos estados ibero-americanos se reuniram em Lima, onde debateram a questão do asilo diplomático sem chegar a um acordo. O primeiro documento firmado foi produzido pela I Conferência Sul-Americana sobre Direito Internacional Privado, realizada em Montevidéu, em 1889. Um Tratado de Paz e Amizade foi assinado em dezembro de 1907 pelos representantes de Costa Rica, Guatemala, Honduras, Nicarágua e El Salvador em Washington, D.C., com o objetivo de alcançar estabilidade no istmo. Os compactuantes se comprometeram a não permitir que dirigentes e ativistas políticos residentes nas regiões de fronteira entre os países perturbassem a tranquilidade do país receptor. Em 1911, os países andinos chegaram a um acordo sobre a extradição em um congresso realizado em Caracas. Os países da América Central chegaram a um acordo paralelo, na Guatemala, em 1934. Em Havana (1928), Montevidéu (1933 e 1939) e Caracas (1954), foram assinados tratados interamericanos em matéria de asilo e de refúgio políticos. O tratado de 1928 negou o direito de asilo aos delinquentes comuns e estabeleceu normas de extradição àqueles que se haviam refugiado em delegações, ou em navios, acampamentos ou aeronaves militares, ou em território estrangeiro. Ao mesmo tempo, o tratado indicava que o asilo de delinquentes políticos seria respeitado, porém seria cumprido somente provisoriamente nas delegações ou no âmbito de estabelecimentos das Forças Armadas, sem permitir que os asilados desembarcassem em território nacional. A Convenção sobre Asilo Político de 1933 acrescentava que a qualificação da delinquência política era de responsabilidade do Estado que presta o asilo. A maioria das nações da América aderiu ao tratado e o ratificou, com exceção da Venezuela, da Bolívia e dos Estados Unidos. Em 1939, em Montevidéu, esses entendimentos se reuniram em um tratado regional mais amplo.

A X Conferência Interamericana realizou, em 1954, uma convenção sobre asilo diplomático e outra sobre asilo territorial. A primeira, que mantinha a linha das convenções anteriores, declarava, em seu art. 2o, que "todo Estado tem direito a conceder asilo; entretanto não está obrigado a outorgá-lo nem a declarar por que o nega". Isso reflete o consenso, advindo durante o período entre guerras, relativo à percepção de outorga de asilo como prerrogativa do Estado, a ser concedida pelos estados individuais em consideração à gravidade e à natureza do delito político cometido. A segunda convenção, relacionada ao asilo territorial, trazia o direito dos estados a admitir dentro de seu território e em exercício de sua soberania - "as pessoas que julguem convenien- 
tes, sem que por causa do exercício desse direito nenhum outro Estado possa manifestar qualquer tipo de oposição".

A Conferência Interamericana de Caracas ratificou normas precedentes e agregou novas normativas em consequência do famoso caso de Víctor Raúl Haya de la Torre, fundador da Apra (Alianza Popular Revolucionaria Americana) no Peru. Com seu partido desterrado em 1948, Haya de la Torre passou cinco anos detido, sob asilo diplomático, na Embaixada da Colômbia, em Lima. Colômbia e Peru apresentaram o caso ante a Corte Internacional de Justiça, que reconheceu, em sua sentença de novembro de 1950, que a proteção havia sido indevidamente concedida. Entretanto, como o Peru também havia exigido que a Corte sancionasse a entrega de Haya de la Torre às autoridades peruanas, o Tribunal de Justiça declarou, em junho de 1951, que, apesar de o Peru haver estado legalmente facultado a exigir que o asilo cessasse, não existia obrigação por parte da Colômbia de entregar Haya de la Torre, já que isso iria contra a tradição latino-americana de asilo, segundo a qual se tratava de um refugiado político que não deveria ser objeto de extradição. A Corte reconheceu, em sua sentença, a situação de paralisia entre ambos os estados. Segundo as convenções de asilo, o asilo diplomático é uma medida temporária que visa à proteção dos "delinquentes políticos", devendo terminar tão logo seja possível. Contudo, a Convenção não apresenta uma resposta clara à questão sobre como se deve dar por concluído o asilo. Quanto aos delinquentes comuns, exige-se expressamente que sejam entregues às autoridades locais. Para os delinquentes políticos, prescreve-se a concessão de um salvo-conduto para sair do país. O salvo-conduto, no entanto, pode ser reclamado somente se o asilo for concedido e mantido de forma regular e se o estado houver requerido que os refugiados sejam enviados para fora do país (International Court of Justice, 1951). O Tribunal optou por não apresentar uma solução prática, sugerindo às partes que buscassem orientação "nas considerações de cortesia e de boa vizinhança, que em matéria de asilo têm tido sempre um lugar de destaque nas relações entre as Repúblicas da América Latina". Somente em 1954, o governo peruano finalmente concedeu um salvo-conduto para que Haya de la Torre pudesse sair do Peru, após anos de amarga denúncia por parte dos liberais em todo o hemisfério ocidental, depois de o caso ter sido levado à Corte Internacional de Justiça em 1950 e em 1951 (Luna, 1962:39-40). 
Os países ibero-americanos também debateram o asilo territorial, inclusive antes de o assunto alcançar repercussão mundial, após a Segunda Guerra Mundial. No âmbito internacional, a criação do Alto Comissariado das Nações Unidas para Refugiados (ACNUR; em inglês, UNHCR), em 1949, marcou a difusão da preocupação para com o problema do desterro massivo, elaborando a figura dos refugiados como correlata ao caso da Segunda Guerra Mundial. Segundo a carta do ACNUR, cuja âncora conceitual foi elaborada contemplando as circunstâncias históricas concretas do pós-guerra, um refugiado político é qualquer pessoa que,

em virtude de fundados temores de ser perseguida por motivos de raça, religião, nacionalidade, pertencimento a determinado grupo social ou opiniões políticas, se encontre fora do país de sua nacionalidade e não possa ou, por causa de ditos temores, não queira recorrer à proteção de tal país; ou que, carecendo de nacionalidade e encontrando-se, em consequência de tais acontecimentos, fora do país onde antes residiu habitualmente, não possa ou, por causa de ditos temores, não queira regressar a esse país (ACNUR, 1951).

Junto com os refugiados - que a partir do pós-guerra puderam receber a assistência do ACNUR, uma vez reconhecido seu status -, persistiu a dinâmica de saída massiva de exilados. Diferentemente do refugiado, o exilado não possui o direito de receber determinados benefícios, salvo a possibilidade de residir no país anfitrião sem ser expulso ou repatriado contra sua vontade.

\section{EXÍLIO MASSIVO: A OUTRA FACE DA AMPLIAÇÃO POLÍTICA}

Comparativamente, os países ibero-americanos experimentaram um número limitado de guerras internacionais, mas se viram imersos em constantes conflitos internos (Centeno, 1999; Kacowicz, 2005), e um dos resultados têm sido as recorrentes ondas de exílio.

Entre o fim do século XIX e o início do século XX, intensificou-se a integração econômica das sociedades ibero-americanas na divisão internacional do trabalho e nos mercados capitalistas, com sua consequente pressão sobre a força laboral e sobre o regime de terras, enquanto os estados ampliavam seu domínio sobre o território "nacional", seja pela via do extermínio dos povos originários, seja por sua subjugação como força de trabalho dominada. Com o aumento das pressões, surgiram também movimentos de resistência, contra os quais governos e elites 
sociais aplicaram mecanismos progressivamente repressivos de controle e de regulação política e social. Nesse contexto, foi natural presenciar de que maneira o exílio - que já se encontrava codificado na cultura política desses países desde o primeiro século de vida independente - se intensificou como importante mecanismo de exclusão institucionalizada não somente contra indivíduos da classe política desgraçados, mas também, cada vez mais, contra ativistas e simpatizantes das classes médias e populares que se haviam incorporado recentemente à política.

É a partir desse período que os países de maior potência na região atravessaram um processo acelerado de industrialização e de diversificação de suas estruturas sociais, incluindo uma crescente classe trabalhadora urbana com participação direta nos setores produtivos e nos serviços relacionados. Ao mesmo tempo, as burocracias estatais se haviam ampliado nas dimensões nacional, estatal, regional e municipal. Esses setores penetraram cada vez mais na esfera do domínio público, a princípio apoiando confrontos entre segmentos das elites tradicionais e, de maneira progressiva, como parte de diferentes conjuntos de aliança, que mobilizavam as massas por meio da promoção e do apoio às demandas setoriais. Paralelamente à modernização econômica e social, aumentaram também o ativismo político e a filiação a partidos políticos ou a organizações vinculadas, como sindicatos, jornais e associações corporativas ou profissionais, além da presença destacada de estudantes, intelectuais e grupos acadêmicos.

A dinâmica de mútuo reforço de pressões socioeconômicas, de confrontação política e de violência repressiva se inscreve em uma ampla série de enfrentamentos sangrentos e intentos radicais de realização de transformações revolucionárias, como os intentos realizados no México, na Bolívia, em Cuba ou na Nicarágua. A violência repressiva foi igualmente endêmica, mas teve seus ápices: o massacre de Canudos, em 1897, e a guerra do Contestado, em 1912-1916, ambos no Brasil; a matança de Santa Maria de Iquique, no Chile, em 1907; a Semana Trágica repleta de repressão ao anarquismo, gerando pogroms na Argentina, em 1919; as diversas intervenções dos Estados Unidos na América Central e no Caribe; a guerra civil na Costa Rica, em 1948; o assassinato de Jorge Eliécer Gaitán, o qual deu início à "década da violência" na Colômbia; os ciclos de guerra de guerrilhas e a repressão, durante duas gerações, a partir da década de 1950, na Guatemala. A magnitude da violência impregnou esses variados casos de contestação, mobilização 
e repressão, modulados pelo uso exacerbado da retórica política juntamente com o uso mais frequente dos meios de comunicação de massa ${ }^{2}$.

Paradoxalmente, um fator fundamental, subjacente à crescente utilização do exílio político como importante mecanismo de exclusão, foi o desenvolvimento de muitas das características modernas de uma sociedade civil nas diversas partes da América Latina. O funcionamento de uma sociedade civil ativa gerou não somente o fortalecimento das bases da democracia, mas também implicou maior participação política e crescentes demandas por direitos sociais e políticos, redistribuição igualitária e transparência institucional. Em âmbitos mais estáveis, essas demandas poderiam ter sido canalizadas em prol do fortalecimento da democracia. Contudo, no contexto ibero-americano, foram interpretadas como pressões revolucionárias, retórica de mobilização popular e ameaça à ordem estabelecida e aos fortes grupos de interesse. A falta de institucionalidade democrática dos estados e dos partidos políticos contribuiu então para reforçar a polarização política, criando um círculo vicioso no qual o temor à revolução provocava repressão e, simultaneamente, se convertia em fator que empurrava os radicais grupos de esquerda à ação armada. A própria dinâmica da modernização gerava novas forças que os sistemas políticos não haviam conseguido incorporar por meio da institucionalização democrática. Desde uma perspectiva política, o populismo e o clientelismo foram utilizados com a finalidade de incluir esses novos estratos, porém em formatos que não fomentaram a autonomia e a representação democrática, $\mathrm{o}$ que viria a intensificar, em um contexto de conflito, a instabilidade institucional. De diversas maneiras, as Forças Armadas se perfilaram como fator de poder decisivo e, em muitos casos, assumiram direta ou indiretamente o poder com a missão de estabelecer uma nova ordem baseada nas doutrinas da segurança nacional. É nessa etapa que a repressão ultrapassa limites anteriores de classe e se projeta não somente sobre os implicados diretamente na violência política mas também sobre amplos segmentos da sociedade civil, vistos como focos ou sustentáculos da subversão da ordem estabelecida.

Os processos que atuavam por trás da utilização do exílio político desde o século XIX sofreram transformações. Os exilados incluíam agora tanto membros da elite política quanto uma ampla gama de ativistas políticos, sindicalistas, intelectuais, estudantes e até mesmo pessoas desconectadas de qualquer atividade pública ou participação política. A nova lógica de desmobilização afetava indivíduos de todos os seg- 
mentos sociais. Ao mesmo tempo que professavam neutralidade em termos políticos, os governos autoritários, especificamente aqueles liderados pelas Forças Armadas, preferiam ver a si mesmos como reserva moral da nação e guardião de seus valores perenes. Nesse contexto, o exílio chegou a ser conceituado como um mecanismo para a exclusão total daqueles que eram retratados como "inimigo". Este não era um inimigo que apenas não deveria retornar à pátria e reatar seu antigo papel social e político quando as circunstâncias o permitissem. Tratava-se de um inimigo que deveria ser totalmente excluído, seja mediante a eliminação física, seja por meio do exílio permanente.

Os regimes autoritários reformularam, portanto, os critérios de inclusão e de exclusão de acordo com seus próprios princípios ideológicos. Desde o início, categorias inteiras de indivíduos e de organizações foram consideradas inimigas da pátria, tendo, assim, de ser excluídas institucionalmente. Com o objetivo de eliminar pessoas ligadas a ideologias alheias, contrárias à nação e a seu espírito, à tradição, ao bem-estar comum e ao futuro da pátria, ampliou-se a rede repressiva. O marxismo, o leninismo, o trotskismo, o socialismo, o comunismo, o liberalismo de esquerda, a esquerda cristã, algumas formas de populismo e quem promovia essas ideologias ou simplesmente simpatizava com elas aos olhos dos detentores do poder deveriam ser marginalizados ou eliminados, já que representavam uma ameaça à nação e a seus respectivos "valores".

As doutrinas de segurança nacional determinariam critérios extensivos de exclusão, que, por sua vez, seriam aplicados com diversos graus de autonomia e interpretação, por meio de diferentes mecanismos de repressão. Entre as vítimas estavam "alvos" tão variados quanto um professor que ensinava o marxismo ou outras "doutrinas exóticas"; dirigentes sindicais e sindicalistas que lutavam por maiores benefícios; estudantes de ensino médio que haviam interpelado as autoridades com suas demandas por redução das tarifas do transporte público; sacerdotes que haviam defendido os pobres em suas paróquias; advogados comprometidos com a causa dos direitos humanos; oficiais de segurança que se haviam negado a disparar contra estudantes em manifestações; membros de certas disciplinas acadêmicas suspeitas, especialmente humanidades e ciências sociais, como psicologia, sociologia e ciência política; artistas que haviam expressado seu protesto contra a injustiça social e a opressão; e todo tipo de organizações - desde partidos políticos até associações profissionais e associações de vizinhos - 
seduzidas, segundo a ótica dos governantes, por ideias antinacionais, antiocidentais e anticristãs. Em alguns dos países, chegou-se até mesmo a queimar livros perigosos, regulamentar a vestimenta ou o corte de cabelo dos jovens e proibir a radiodifusão de música "subversiva".

Nessa etapa, o exílio se transforma funcionalmente em um mecanismo regulador dos estados-nação, centrado em torno da política e das esferas públicas nacionais, e projetando-se nos âmbitos transnacional e transcontinental.

\section{A FORMAÇÃO DE UMA ESTRUTURA QUÁDRUPLA DO EXÍLIO}

No século XIX, a estrutura triangular do exílio se baseava nas tensas relações entre a agenda dos exilados, as considerações políticas dos países de acolhimento e as pressões exercidas pelos países de origem, todas emolduradas em um contexto de fragmentação política e administrativa (ver Figura 1).

Essa estrutura formal predominou enquanto os estados foram os atores centrais no âmbito internacional. A promessa da Revolução Francesa, em termos de direitos do indivíduo e do cidadão, submeteu-se às transformações e às supressões do império napoleônico e da restauração do antigo regime operada pela Santa Aliança. O ressurgimento liberal de 1848 na Europa, muito vinculado ao nacionalismo, concentrou-se no interior dos espaços públicos dos antigos e novos estados-nação. Muito embora a soberania tenha sido o princípio básico da normatização internacional, as políticas nacionais, em matéria de expulsão dos opositores políticos ao exílio, geraram graves problemas no sistema.

Ainda durante o século XX, os países continuaram utilizando os exilados como peões em suas estratégias internacionais. Um bom exemplo é a situação em uma data tão tardia como a Primeira Guerra Mundial, quando o papel dos exilados políticos se conjuga com uma Revolutionierungspolitik, quer dizer, com a política que um país joga contra outro mediante o uso de exilados políticos, emigrantes e outros agentes, enquanto os exilados fazem uso dos espaços discursivos e políticos abertos nos países de acolhimento a fim de lograr um resultado determinado no país de origem. Entre os casos mais famosos dessa estrutura tríplice na Europa estão os movimentos de Roman Dmowski, do Movimento Nacional Polonês, e de Thomas Masaryk, do Movimento Nacional Tcheco, que conduziram movimentos populares em Paris contra os 
Impérios Centrais, ou o de Vladimir Ilych Lenin, líder dos bolcheviques, enviado pelos alemães em um vagão lacrado à Rússia, via Suécia e Finlândia, a fim de impulsionar a queda dos Romanov e a saída da Rússia da Primeira Guerra Mundial.

Nas Américas, um dos casos mais notáveis é o dos exilados cubanos que começaram a se trasladar para os Estados Unidos na década de 1920. Apesar de os exilados terem sido somente parte de uma comunidade mais ampla de cubanos - muitos deles trabalhadores na indústria do tabaco -, protagonizaram papéis cada vez mais influentes na determinação das decisões políticas nos Estados Unidos, de forma paralela aos interesses econômicos e políticos de seu país de origem. Cabe lembrar o progressivo passo dos Estados Unidos em pressionar a favor da demissão do presidente cubano Gerardo Machado no início da década de 1930. No entanto, a crise econômica e as dificuldades instaladas resultaram em protesto generalizado, reprimido severamente pela administração Machado. A violência institucionalizada produzira centenas de exilados que escaparam para os Estados Unidos, sobretudo para a Flórida e para Nova York, onde foi mantida uma forte campanha contra o caudilho cubano, com uma minoria propondo a intervenção direta dos Estados Unidos. A presença de uma imprensa cubana opositora nos Estados Unidos desempenhou um papel importante nas decisões adotadas pela administração Roosevelt em abster-se de prestar maior apoio a Machado, acelerando, portanto, sua fuga de Cuba e a série de acontecimentos que logo alçaria Fulgêncio Batista ao poder. À parte os detalhes particulares desse e de outros casos de exílio político nas Américas e em outras regiões, nota-se como os exilados se moviam dentro de uma estrutura triangular, na qual quase não havia espaços institucionais no plano internacional que pudessem servir como ambiente eficaz para o debate e a regulamentação de questões relacionadas ao exílio político, além de uma fonte de pressão sobre os estados-membros da comunidade internacional.

Com a evolução do cenário mundial e a criação de redes transnacionais, a formação de comunicações e fóruns internacionais em que os problemas do direito internacional e os direitos humanos poderiam ser elaborados, a estrutura de exílio sofreu uma transformação básica. Uma vez que o elemento transnacional entra na equação do exílio como um fator de peso, os exilados políticos no exterior adquirem cada vez mais ressonância internacional e nacional à custa de âmbito delimitado pelas fronteiras nacionais. Gera-se, assim, uma estrutura quá- 
Figura 2

Estrutura quádrupla do exílio político

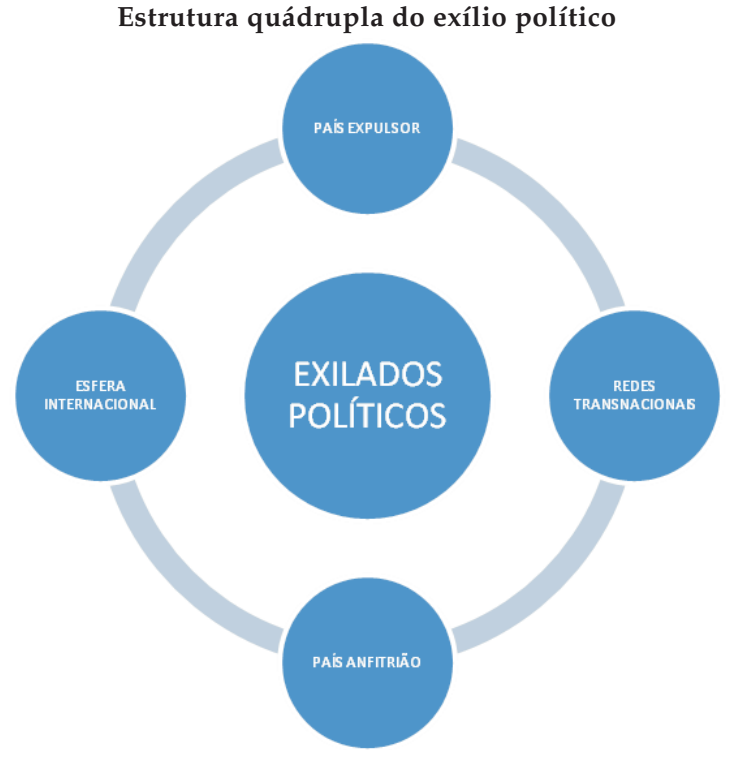

drupla, em que os exilados somam potencialidade por meio das redes transnacionais, cuja presença permite a cristalização de coalizões políticas portadoras de nova voz na esfera internacional e com maior poder de pressão tanto sobre os estados expulsores quanto sobre os estados anfitriões (ver Figura 2).

Essa estrutura de exílio vem se estabelecendo progressivamente na América Latina. Nesta seção, é analisado um dos primeiros indícios parcial, todavia - da transição da política tríplice à estrutura quádrupla do exílio, tal como se desenvolveu na década de 1950 no Caribe e na América Central, quando uma série de ditaduras gerou ondas de exilados que se dispersaram por toda a região.

Gerou-se então uma intensa atividade de grupos de exilados dos estados daquela região, particularmente na Guatemala, na Nicarágua, em Cuba, na Venezuela e na República Dominicana. Em 1952, praticamente todo o Caribe hispano-falante estava dominado por ditadores que suprimiam a oposição interna, até o ponto de a oposição política na zona ser possível quase que exclusivamente no âmbito das redes que os exilados lograram criar e manter no exterior.

A efervescente atividade dos exilados criou laços transnacionais nos principais centros de atividade do exílio caribenho, situados nesse mo- 
mento na Cidade do México, em San José da Costa Rica, em San Juan de Porto Rico, em Miami e em Nova York. Cerca de mil ativistas da Ação Democrática (AD) da Venezuela se concentraram no México, em torno da liderança de Rómulo Gallegos. Os dominicanos se distribuíram por toda a América Central e o Caribe, concentrando-se sobretudo em San Juan e em Nova York. Miami foi o tradicional bastião dos cubanos, também ativos no México, em San Juan e em Nova York. Os nicaraguenses e hondurenhos preferiram o México e, dependendo das circunstâncias, trasladaram-se também para San José da Costa Rica. Os exilados mais militantes, de todas as nacionalidades, se encontravam na Guatemala de Jacobo Arbenz Guzmán, por sua vez deposto pelo golpe de Estado que obrigou o presidente, assim como muitos outros cidadãos e asilados, a se exilar ${ }^{3}$.

Os partidos arrecadavam fundos mediante contribuições voluntárias e, ocasionalmente, por meio de atividades e sorteios. Além de suas atividades políticas, os exilados se ocupavam da escrita, da docência e da oratória pública, em parte porque essa era sua maneira de se sustentar economicamente, mas também com a finalidade de projetar a causa no Caribe, na América Central e na América do Norte através dessas atividades. O ex-presidente venezuelano Rómulo Gallegos, por exemplo, deposto por um golpe militar em novembro de 1948, foi um destacado escritor e orador popular, cujas reputação e relevância no México e em todas as Américas centralizavam a causa do exílio. Outros eram estudantes, uma categoria nem sempre bem-vinda, já que tendia a ser ativa politicamente. Em 1956, o governo de Honduras tentou persuadir os estudantes guatemaltecos exilados a se mudarem para a Costa Rica, tratando assim de evitar que agitassem o corpo estudantil local.

Os exilados não estavam totalmente fora do alcance dos ditadores do Caribe. Os dominicanos, em particular, foram cuidadosamente vigiados pela rede de espionagem de Rafael Leónidas Trujillo, que utilizava os serviços diplomáticos e consulares para hostilizar e mesmo liquidar seus inimigos. Depois de 1956, Fulgêncio Batista e Trujillo haviam planejado juntos o assassinato do presidente da Costa Rica, José Figueres, que apoiava a esquerda democrática exilada. Em 1957, os agentes de Trujillo manipularam numerosas intrigas no México e na América Central. Trujillo possuía amigos, no Congresso dos Estados Unidos, que se sentiam atraídos por sua política anticomunista; graças a isso, foi capaz de manter estreita vigilância sobre as atividades dos exilados. Por outro lado, ocasionalmente pretendeu cooptar seus antago- 
nistas com ofertas de dinheiro e promessas de anistia. Em 1955, o Congresso da República Dominicana aprovou uma lei de anistia, e Trujillo anunciou que o governo ajudaria financeiramente os exilados que buscassem a repatriação. Marcos Pérez Jiménez também tentou alcançar um acordo com seus inimigos, especialmente tratando de eliminar Rómulo Betancourt e exercendo pressão sobre os países de acolhimento para que o expulsassem de seus territórios, ou que ao menos limitassem seus movimentos.

Nessa etapa, ainda se desenvolvia uma política de pressões e de contrapressões entre os países expulsores e os países anfitriões, na qual os primeiros exigiam que os segundos controlassem os exilados que haviam encontrado asilo em seu território. O México, por exemplo, tentava projetar uma imagem de país de acolhimento para os perseguidos políticos de outros países ibero-americanos, mas, ainda que respeitasse $o$ direito de asilo, suas autoridades vigiavam cuidadosamente as atividades dos exilados. Em 1953, por exemplo, quando se descobriu que, nos ataques de Fidel Castro, em Cuba, foram utilizadas armas mexicanas, os mexicanos se comprometeram a realizar esforços para prevenir o contrabando de armas para Cuba e expulsaram dois exilados cubanos. Em 1956, Castro, Che Guevara e outros foram detidos sob a acusação de conspirar em ação revolucionária contra Batista. Não obstante, antes do fim desse ano, Fidel Castro já havia invadido Cuba usando a península de Iucatã como trampolim de desembarque na ilha. Provavelmente, como resultado dessa experiência, o México viria a expulsar, em 1957, 550 estrangeiros "indesejáveis", alguns dos quais contratados nas ações políticas consideradas perigosas ou embaraçosas para o governo mexicano. Por essa razão, e uma vez que Marcos Pérez Jiménez fora derrocado na Venezuela, os exilados cubanos passaram a trasladar-se para Caracas em 1958. Os Estados Unidos seguiram adotando uma política similar quanto aos exilados cubanos, oferecendo-lhes refúgio, porém sem tolerar violações a suas leis de residência (Yankelevich, 2002; Sznajder e Roniger, 2007).

Na década de 1944-1954, a Guatemala também foi um lugar de asilo que atraiu numerosos exilados de toda a região, entre os quais destacados líderes comunistas que vieram a atuar inclusive em assuntos políticos do país anfitrião. Os líderes comunistas cubanos foram visitantes frequentes, colaborando com os marxistas locais para controlar o trabalho organizado. Os comunistas salvadorenhos foram os mais ativos. Os ativistas do Partido Socialista Popular Dominicano, que era o parti- 
do comunista da República Dominicana no exílio, também aderiram ao Partido Guatemalteco del Trabajo. Em 1952, eles se comprometeram a organizar todos os dominicanos exilados espalhados pelo mundo em torno de um Comitê de Exilados Dominicanos. Outros grupos nacionais no exílio estabeleceram frentes unidas similares na Guatemala, entre elas a Asociación Salvadoreña Democrática, o movimento de nicaraguenses partidários da democracia e o Partido Democrático Revolucionario Hondureño. O exílio republicano espanhol também se destacava, e os diferentes grupos se uniram para formar o Frente Democrático de Exiliados Americanos e Españoles. No desfile de maio de 1953, os grupos de exilados marcharam com 70.000 partidários a fim de manifestar sua lealdade ao presidente Arbenz. Ao mesmo tempo, a Guatemala seguia lutando ativamente contra os ditadores do Caribe. Com a queda de Arbenz em junho de 1954, os exilados tiveram de fugir da Guatemala. Após a fuga, Castillo Armas incluiu seus nomes em uma lista de agentes comunistas que estavam proibidos de regressar à Guatemala. A lista também incluía não comunistas, como os líderes da $\mathrm{AD}$, e Juan Bosch, do Partido Revolucionario Dominicano (PRD).

A AD foi a maior e mais bem organizada entidade de exilados da região, sendo Rómulo Gallegos seu porta-voz no México e Luis Augusto Dubue seu líder na Costa Rica; e incluiu um Comitê de Coordenação, também dirigido por Dubue. O maior número de ativistas se concentrava no México, onde mantinham a estrutura partidária e uma intensa atividade. A Confederação de Trabalhadores da Venezuela no exílio, sob a direção de militantes da $\mathrm{AD}$, colaborava estreitamente com o movimento sindical livre na escala internacional. A juventude da AD dava especial atenção aos assuntos estudantis; entre 1955 e 1957, editaram, no México, um importante periódico, o Venezuela Democrática. A comunidade celebrava reuniões públicas em homenagem aos mártires sucumbidos tanto no exílio quanto em território venezuelano. Durante os primeiros quatro anos e meio de exílio, os dirigentes da AD se preocuparam em assegurar uma rede de comunicação confiável com seus companheiros de resistência na Venezuela, dirigindo suas atividades desde o exterior do país e promovendo a causa venezuelana ante a Organização das Nações Unidas (ONU). O fechamento das colônias penais em 1949 e em 1952, e a libertação de Valmore Rodríguez (e outros) do cárcere, em 1949, ocorreram graças às denúncias dos exilados realizadas perante a ONU. Eles também obtiveram êxito na organização de um boicote à Conferência da Comissão do Petróleo, da Organi- 
zação Internacional do Trabalho, realizada em Caracas em 1955, ocasião na qual importantes sindicatos se negaram a enviar representantes. A AD também encabeçou uma estratégia de cooperação com outros partidos opositores no exílio, inspirada tanto na convicção de que a maré rapidamente se voltaria contra os ditadores quanto na expectativa do término do mandato de Pérez Jiménez em fins de 1957. A agitação posterior às eleições livres converteu-se na base para a unificação dos grupos da oposição venezuelana. Depois de um plebiscito orquestrado a fim de permitir a permanência de Pérez Jiménez no poder, a arena política tornou-se caótica. Uma revolta militar contra Pérez Jiménez, em janeiro de 1958, conduziu à sua eventual destituição. Quando a AD finalmente recuperou o poder, continuou lutando contra os demais ditadores do Caribe.

As organizações políticas dos exilados eram fruto do exílio. Na República Dominicana, não houve verdadeiros partidos políticos antes de Trujillo; com a ascensão do ditador, os partidos políticos não foram mais tolerados. A formação mais semelhante a um partido político, realizada pelos dominicanos, no sentido moderno do termo, foi o PRD, fundado em Havana, em 1939, por Juan Bosch e Ángel Miolán, com filiais em Porto Rico e em Nova York. Outros grupos - todos fundados no exílio - se haviam fragmentado em porções de seguidores de líderes, no velho estilo clientelista. À parte os comunistas, somente uma dessas organizações do exílio perdurou por anos: a Vanguarda Revolucionária Dominicana, em Porto Rico, fundada em 1956, com filiais no México e em Nova York. Apesar da ditadura de Batista, sua sede foi mantida em Cuba até 1958, quando foi trasladada para Caracas. Poucos partidos da esquerda democrática conheceram o mesmo êxito no exílio, provavelmente porque nenhum deles esteve tão bem organizado como a AD. Os exilados cubanos estavam profundamente divididos em certo número de partidos rivais, incluindo o Partido Popular Ortodoxo e o comunista Partido Socialista Popular. Os autênticos estavam atomizados em facções e lideranças personalistas, e dificilmente despertavam simpatia, ao mesmo tempo que muitos cubanos estavam decepcionados com sua liderança. Não é de surpreender, portanto, que se dedicaram mais a atividades conspiratórias do que a uma elaboração política partidária. Os exilados da República Dominicana haviam estado no exterior por mais tempo, alguns desde 1930. Ao exilar-se em 1955, Germán Ornes queixou-se por haver deparado com uma "aristocracia do exílio", na qual os que estavam no exílio por mais 
tempo observavam com receio os recém-chegados e os consideravam colaboracionistas.

Por causa dos contatos transnacionais de Bosch com dirigentes democráticos e organizações de exilados, foi possível obter fortes denúncias contra Rafael Trujillo no âmbito internacional. Ainda assim, as atividades dos exilados dominicanos em Nova York se caracterizavam por serem coalizões instáveis. Seus protestos e manifestações não podiam demolir a ditadura de Trujillo, porém suas atividades tiveram importantes efeitos: rechaçaram as demandas de Trujillo por total submissão e contribuíram para modificar a imagem do ditador nos Estados Unidos, criando assim uma transformação política. As reações exageradas de Trujillo às atividades dos exilados provocaram desprezo para com seu governo. Apesar das divergências entre facções, o PRD desenvolveu uma estrutura partidária e adquiriu suficiente prestígio para que, chegado o momento, pudesse oferecer uma alternativa democrática. Ao deixar o exílio, o PRD se livrou de toda e qualquer suspeita colaboracionista.

A ditadura de Anastasio Somoza García, na Nicarágua, foi outro fator determinante na criação de grupos de resistência no exílio, sobretudo na Costa Rica. Em 1953, Pablo Leal usou a Costa Rica como base para a geração de apoio a seu movimento contra Somoza. De lá se trasladou para Miami, onde Prío Socarrás se comprometeu a apoiá-lo e lhe deu instruções para estabelecer contato com seus representantes na Cidade do México. Com a ajuda de Socarrás, armas foram enviadas à Costa Rica e, finalmente, introduzidas na Nicarágua por meio de contrabando. Leal viajou então para a Guatemala, onde recrutou nicaraguenses para a Revolução. No fim de 1953, esses grupos partiram da Guatemala para a Costa Rica, onde Leal realizou os preparativos finais, incluindo a formação de um Partido Nacional Revolucionario. Pablo Leal também se reuniu com figuras como Bosch e Betancourt, e com o cubano Sergio Pérez, que o ajudaram na aquisição de armas. Dos 21 companheiros que finalmente se juntaram a Leal em direção à Nicarágua, havia 16 nicaraguenses e cinco de outras nacionalidades. A expedição resultou na morte de vários, entre eles Amadeo Soler, um amigo do dominicano Juan Bosch. Rómulo Betancourt foi descrito como o mentor do plano e foi forçado a partir rumo a um novo local de exílio. Somoza foi assassinado em 1956 por Rigoberto López Pérez, um jovem poeta marxista que estivera exilado em El Salvador. Isso, somado à solidariedade demonstrada pelos salvadorenhos para com o assassino de So- 
moza, fez com que as relações entre Nicarágua e El Salvador se tornassem tensas. Especialmente forte foi a demanda que a Nicarágua dirigiu a El Salvador no sentido de que deveria controlar os nicaraguenses exilados, demandando também a extradição de alguns deles. El Salvador se negou a extraditar os exilados por questões políticas, reiterando a política de asilo sempre que as pessoas deslocadas se abstivessem de atividades políticas em seu território. De maneira similar, nicaraguenses exilados em Honduras se reuniram nas cercanias da fronteira e, desfrutando de liberdade sob o governo de esquerda democrática de Ramón Villeda Morales, planejaram a invasão à sua pátria. Não obstante, as atividades dos exilados antissomozistas não correspondiam exatamente aos interesses dos anfitriões, daí que o governo hondurenho veio a internar os possíveis invasores e a tomar medidas para deportá-los para a Guatemala a fim de impedir que tomassem parte na insurgência.

Os países da América Central e do Caribe entraram na Guerra Fria com várias de suas esferas políticas em estado de agitação. A dinâmica política se caracterizou então por oscilações periódicas entre democracia e ditadura, e entre a redefinição das linhas da adaptação e a geração de fluxos de exilados políticos. Por diferentes razões, o México e a Costa Rica se converteram em locais de asilo. A Guatemala o foi até o golpe de 1954; a Venezuela, após o retorno à democracia em 1958. As embaixadas da Colômbia também foram fundamentais para a concessão de asilo a muitos que aspiraram se exilar, pois, apesar da violência que irrompeu nesse país no fim da década de 1940, tratava-se de uma região cuja democracia se fez presente. Cuba desempenhou um papel ambíguo atuando como país de acolhida para os exilados da América Latina ao mesmo tempo que gerava ondas de exilados entre seus próprios cidadãos. Da mesma forma, enquanto perseguia a oposição política e se considerava uma força de vanguarda na luta contra o comunismo, a ditadura de Trujillo, na República Dominicana, acolheu exilados variados, inclusive refugiados da Guerra Civil Espanhola (1936-1939), refugiados judeus da Europa, que tentavam escapar da barbárie nazista os quais poucos países estavam dispostos a aceitar -, e mesmo presidentes depostos, como no caso de Perón na década de 1950. O próprio Rafael Trujillo alegou, orgulhoso, ser o arquiteto de uma doutrina diplomática de asilo humanitário, baseada na alternativa de refúgio que ofereceu a judeus que escapavam da Europa (Kaplan, 2008).

Devemos reconhecer que tanto os países autoritários quanto os democráticos promoveram uma política ambígua em relação ao exílio e ao 
asilo. Embora os países autoritários tenham sido os que tipicamente usaram esse mecanismo de exclusão no que tange às oposições políticas, eles também ofereceram asilo a habitantes de outros países. De maneira similar, administrações democráticas, como as da Costa Rica e do Chile - que ofereceram refúgio a exilados políticos de outros países da Ibero-América -, também utilizaram a expulsão como meio de acertar contas com suas oposições. Na Costa Rica, por exemplo, José Figueres, um político e empresário econômico, viu-se obrigado a exilar-se no México entre 1942 e 1944 por causa de sua crítica ao democraticamente eleito presidente Rafael Ángel Calderón. No México, Figueres se uniu a um grupo de políticos de outros estados ibero-americanos em situação similar a fim de formar a Legião do Caribe, uma rede transnacional que conspiraria contra governos da República Dominicana, da Venezuela, da Nicarágua e da Costa Rica. As políticas de Calderón de expropriação de bens alemães no contexto da Segunda Guerra Mundial alienaram os produtores de café de origem alemã, bem como muitos conservadores que apoiavam Figueres. Em 1948, uma situação de polarização política e de resultados eleitorais impugnados resultou em uma curta, porém sangrenta, guerra civil. Quando Figueres tomou o poder, encabeçando uma junta de governo, Calderón foi quem se viu obrigado a fugir rumo ao exílio, trasladando-se para a Nicarágua e logo para o México, onde permaneceu por quase uma década.

Durante o período estudado, a dimensão transnacional de redes de solidariedade já é um fator emergente, mas ainda está submetida a uma estrutura básica tríplice de pressões e de contrapressões entre os países expulsores, os países receptores e as redes de exilados que se trasladaram para o exterior para reativar sua capacidade de luta contra os governos que forçaram o desterro. Uma geração mais tarde, já nas etapas avançadas da Guerra Fria, a dimensão transnacional adquire maior amplitude na equação do exílio ibero-americano.

\section{A FUNCIONALIDADE CAMBIANTE DO EXÍLIO NA GUERRA FRIA}

Quando os países tiveram de enfrentar a falta de um modelo viável de desenvolvimento, a mobilização de massas, a polarização política e o dilema de levar a cabo reformas ou expor-se às ameaças revolucionárias, viram-se acuados pelas antinomias da Guerra Fria e das doutrinas de segurança nacional, que transformaram toda a região em um cenário de violência generalizada e de exclusão política. Com a intensificação dos enfrentamentos nos anos 1960 e 1970, ampliou-se o uso do exí- 
lio político como mecanismo de exclusão forçada, cada vez mais e mais comum. Os exilados políticos ibero-americanos dispersaram-se então por toda a Ibero-América, Estados Unidos, Canadá, Europa Ocidental, bloco comunista e mesmo por localidades em países distantes, como Israel, Argélia, Serra Leoa, Austrália e Moçambique*.

Levou tempo até que os governantes autoritários, no poder em distintos países da América Latina durante a Guerra Fria, compreendessem a profunda transformação que se operava na funcionalidade do exílio. No início, os governos de fato continuaram abusando do exílio como mecanismo institucionalizado de exclusão política, pensando que os cidadãos expulsos, ou que escaparam para o exterior, seriam relegados a uma exclusão permanente da política nacional, o que equivaleria a uma morte social e política dos desterrados, complementando assim a desaparição física nos casos em que esta não se viabilizava.

Do ponto de vista dos repressores, o exílio deveria operar um corte definitivo entre os indivíduos desterrados e a política do país de origem. Os governantes autoritários supuseram que, sendo eles parte de uma coalizão mundial de luta aberta contra o comunismo internacional e seus aliados, poderiam suprimir toda oposição usando métodos repressivos, o ostracismo e o desterro, como no passado, com certa impunidade e imunidade a críticas no exterior, críticas que eles poderiam desvirtuar mediante uma política de desinformação nos fóruns internacionais.

Conforme visto, o exílio havia funcionado tradicionalmente sob uma estrutura tríplice, baseada na interação entre as estratégias de exclusão e as pressões exercidas pelos países expulsores, os países anfitriões e as estratégias dos exilados, frequentemente à mercê dos governos do país de asilo. O peso dos dois primeiros fatores refletiu por muito tempo a centralidade dos estados consolidados que, dentro de suas fronteiras, promoviam a consciência nacional por meio da educação, da manipulação simbólica, da administração pública e do serviço militar. Essa estrutura triangular do exílio, presente desde a independência, havia persistido enquanto os estados-nação continuavam sendo os principais atores no cenário internacional, traçando assim diferenciações claras entre as identidades coletivas de colombianos, argentinos, mexicanos, brasileiros, peruanos e as de outras nacionalidades. O conceito de uma "grande pátria" de bases bolivarianas não havia desaparecido, porém persistia às margens da esquerda e da direita, havendo de recu- 
perar-se parcialmente no exílio, no contexto das campanhas de solidariedade e do redescobrimento do destino comum compartilhado com cidadãos originários de outros países da América Latina.

Essa estrutura básica sofreu uma transformação radical na segunda metade do século $X X$, quando as redes transnacionais passaram a atuar como quarto fator, detentor de crescente peso na equação do exílio. Tratou-se de um reposicionamento dos exilados na esfera pública mundial, o que resultou cada vez mais significativo dentro da equação exílica, já que os exilados e as redes de solidariedade internacional se converteram em um dos fatores de maior visibilidade do processo de ampliação do alcance do direito internacional humanitário e da proteção dos direitos humanos a nível global.

Essa tendência resultou, parcialmente, da evolução do caráter transnacional da repressão, que, no contexto dos entendimentos da Operação Condor, chegou ao ponto de assassinar opositores em entornos bastante distantes de seu país de origem, como no célebre caso do assassinato do ex-ministro chileno de Relações Exteriores Orlando Letelier e de sua secretária, Ronni Moffitt, cidadã norte-americana, em 21 de setembro de 1976 em Washington, D.C.; assassinato orquestrado pela Dina (Dirección de Inteligencia Nacional) chilena. A Operação Condor se estenderia para muito além das fronteiras de cada país da América Latina como desdobramento natural da impossibilidade de conter a oposição política tão somente mediante sua exclusão das esferas públicas nacionais. Uma vez que o terror e o medo à perseguição se haviam expandido para além das fronteiras nacionais, os exilados foram capazes de se beneficiar das redes de solidariedade internacional projetando para o exterior a questão da repressão e do exílio, e contribuindo para a sensibilização do grande público no desenvolvimento de um espaço de ativismo transnacional. A contrapartida dessa onda de ampliação da perseguição política foi a internalização dos princípios dos direitos humanos promovida por organizações internacionais no cenário mundial.

Foram fundamentais para essas mudanças organizações como a ONU, a Anistia Internacional, o Conselho Mundial de Igrejas, a Igreja Católica, o ACNUR, a Organização Internacional para as Migrações, a Cruz Vermelha, o Parlamento Europeu e as comissões parlamentares de direitos humanos do mundo inteiro, as associações internacionais de partidos políticos, como a Internacional Socialista e a Internacional Po- 
pular, ou Democrata-Cristã, os partidos irmãos em outros países, as confederações de sindicatos nacionais e internacionais, e uma miríade de organizações não governamentais que se concentraram na defesa dos direitos humanos no exterior de suas fronteiras nacionais. Essa infraestrutura permitiu a rápida criação de uma densa rede de comitês de solidariedade para com as vítimas da repressão que fugiam da perseguição na Ibero-América. No denso cenário organizacional e de redes instrumentais dessa transformação, participaram também associações civis e comitês de solidariedade na Europa e nos Estados Unidos; funcionários nesses países; algumas das administrações de países desenvolvidos interessadas em censurar violações flagrantes de direitos humanos; as redes políticas de apoio aos perseguidos políticos; representantes de poderosos meios de comunicação de impacto internacional, tais como o Washington Post e o New York Times; as comissões internacionais interessadas, como a Comissão Interamericana de Direitos Humanos, com sede em San José da Costa Rica, ou o ACNUR e seus organismos de apoio nacionais, registrando o fluxo massivo de exilados e refugiados ibero-americanos na Europa e em outros países. Em particular, protagonizaram um papel decisivo as organizações de direitos humanos nacionais e transnacionais, como a Anistia Internacional e a Americas Watch, que vieram a ganhar maior visibilidade e respeitabilidade, podendo assim contestar de forma crescente as duvidosas explicações oferecidas pelos estados autoritários quanto a seu desempenho humanitário.

A cristalização de uma esfera pública internacional aberta ao que outrora foram considerados "assuntos internos", a serem resolvidos pelos próprios estados e em caráter da soberania nacional, permitiu a sensibilização da opinião pública mundial. Isso gerou pressões em múltiplas direções, inimaginadas pelos governantes da Ibero-América até então. Assim, a esfera pública internacional se tornou um aspecto crucial adicional no jogo de forças entre os exilados políticos, os países de asilo e os intentos de repressão promovidos pelos países expulsores. Teoricamente, a nova dinâmica do exílio massivo operou na contramão do monopólio dos estados-nação, ao reduzir a pretensão dos estados por direitos soberanos enquanto, simultaneamente, o âmbito internacional e mundial se sensibilizava quanto à proteção dos exilados e à sua autonomia em termos de influência política transnacional.

Esse processo se acelerou após o golpe de estado no Brasil em 1964, tal como o analisa James Green (2003), focalizando-se no movimento de 
solidariedade norte-americano. Os altos e baixos desse movimento estão estreitamente vinculados às questões centrais da política dos Estados Unidos. Foi grande o interesse em apoiar os exilados no final da década de 1960, especialmente entre os intelectuais, os estudantes e o clero, interesse intimamente conectado com a oposição à guerra no Vietnã. Na década de 1970, com a derrota eleitoral de George McGovern e o começo da retirada dos Estados Unidos do Vietnã em 1973, o movimento antiguerra perdeu ímpeto, o que também se refletiu na perda de interesse pelo caso brasileiro. Não obstante, o trabalho em torno do caso brasileiro fixou as bases para o movimento de solidariedade para com o Chile, depois do golpe de Pinochet. Reavivou-se então o interesse pela situação na América Latina. Segundo Green, o caso Watergate e as investigações da comissão parlamentar do senador Frank Church, com respeito aos esforços de Washington para desestabilizar o governo de Allende, trouxeram à tona a profundidade da corrupção da administração de Nixon e proporcionaram um amplo espaço de debate sobre a política de direitos humanos na América Latina ${ }^{5}$. O golpe de Pinochet contra o governo constitucional de Salvador Allende foi um importante foco de reativação da atividade de protesto, impactada pelo enorme sofrimento dos chilenos em busca de asilo nas embaixadas de Santiago, de maneira que, uma vez deslocados para o exterior, pudessem reavivar as redes de solidariedade com os exilados em sua luta pela restauração da democracia e contra as violações dos direitos humanos cometidas pela ditadura. Não menos fundamental na reconstrução da cena internacional foi o impacto da descredibilização das políticas de negação e perseguição de seus cidadãos pelos militares argentinos. Ainda que as autoridades argentinas tenham enveredado por uma política sistemática de desinformação e negação de violações de direitos humanos, alegando que o tema dos desaparecidos era resultado de mentiras difundidas pelas redes de conspiração vinculadas ao comunismo internacional, a crescente evidência, na forma de uma densa rede de críticos nos âmbitos internacional e transnacional, modificou radicalmente o equilíbrio político e discursivo, para benefício dos exilados. Tal dinâmica - reproduzida em diferentes países e em fóruns internacionais, e sustentada por redes na sociedade civil global - fez com que a sorte dos cidadãos perseguidos se tornasse motivo de preocupação para a comunidade internacional (Roniger e Sznajder, 2004).

Aqueles que de fato governavam nos países ibero-americanos se viram obrigados com cada vez mais frequência a afirmar que eram os mais ar- 
dentes defensores dos direitos humanos, reforçando de forma paradoxal a normatização de dito discurso, que veio a se destacar por sobre os demais discursos hegemônicos da soberania nacional, ao menos no nível declaratório. Como consequência dessa transformação, a difícil situação dos exilados passou a ser seguida de perto e examinada, e suas demandas por justiça não puderam ser ignoradas. A partir de então, os exilados encontraram maior receptividade e espaços políticos onde puderam potencializar seu ativismo a favor do fim dos regimes autoritários, da restauração da democracia e, em alguns casos, da demanda por investigação completa sobre o histórico das violações de direitos humanos cometidas pelas ditaduras.

\section{CONCLUSÃO PROGNÓSTICA}

Na última década do século XX, em face do novo cenário da "terceira onda de democratização" e da transformação do cenário internacional e transnacional, parecia que o exílio, como mecanismo de exclusão amplamente usado por governos autoritários, havia chegado a seu fim.

Não obstante e de maneira paradoxal, as duas últimas décadas têm revelado que o exílio continua presente nas novas democracias sob duas formas principais. Uma, derivada de ameaças e de repressão contra jornalistas investigativos e intelectuais. Os jornalistas e intelectuais que, em virtude da democracia, se atreveram a criticar funcionários públicos e dignitários têm sido particularmente sensíveis à perseguição. Dentre os casos conhecidos se destaca o da escritora e jornalista chilena Alejandra Matus, obrigada a escapar para o exterior em abril de 1999, após a publicação de El Libro Negro de la Justicia Chilena. O presidente da Corte Suprema, Servando Jordán, apresentou acusações contra Alejandra afirmando, com base na Lei de Segurança do Estadoherdada do regime militar -, que a crítica contida no livro constituía um "delito contra a ordem pública". Consequentemente, a obra foi confiscada, e Alejandra, que havia recebido ameaças de morte na década de 1980, fugiu para Buenos Aires, estabelecendo-se mais tarde nos Estados Unidos, onde lhe foi concedido o asilo até o Chile aprovar uma nova lei de imprensa em 2001 (Libertad de Prensa, 2006). A nova legislação permitiu que a jornalista regressasse do exílio nos Estados Unidos e retomasse sua carreira no Chile. Não obstante, Alejandra teve de seguir lutando pela liberdade de imprensa. Em 2003, abdicou de colaborar para o jornal La Nación depois de que este se negou a publicar uma de suas notas investigativas sobre um caso de suposta corrupção 
envolvendo a diretoria do Instituto de Desenvolvimento Agrícola e Pecuário (International Development Research Center, 2008).

Similar foi o caso de Baruch Ivcher Bronstein, presidente da Junta de Diretores e dos acionistas majoritários da rede de televisão Frecuencia Latina-Canal 2, no Peru. Ao confrontar elementos do poder com suas notas investigativas, Ivcher perdeu a rede de televisão, foi para o exílio em Miami e continuou sua luta ante organizações internacionais, como a Comissão Interamericana de Direitos Humanos e o Banco Mundial, que, por sua vez, bloqueou um empréstimo para o Peru em virtude da restrição à liberdade de imprensa nesse país. Em represália, o governo peruano ordenou a detenção de colaboradores próximos e abriu uma causa judicial contra Ivcher e seu irmão, por acusação de evasão fiscal relacionada aos anos de 1992-1995. Apesar de o governo peruano ter apresentado um pedido de detenção à Interpol, a suspeita de perseguição política impediu seu processamento. Finalmente, depois da queda de Alberto Fujimori e de Vladimiro Montesinos do poder, e da revogação dos julgamentos pendentes pelo Congresso peruano, Ivcher regressou a Lima no final do ano 2000 para reunir-se à sua esposa e filhas, e retomar sua posição na rede de televisão.

O segundo módulo gerador de exílio massivo sob democracias tem tido lugar em contextos de mudança radical, levada a cabo em situações de pressão sobre a oposição e / ou de radicalização de uma retórica polarizadora, como no caso do Peru, no governo de Alberto Fujimori, ou da Venezuela, no de Hugo Chávez. A onda de expatriação venezuelana, por exemplo, tem praticamente duplicado o tamanho da diáspora venezuelana nos Estados Unidos, a qual, de acordo com dados do censo desse país, passou de um número de 91.507 em 2000 - um ano após Chávez tomar posse de seu cargo - para 177.866 em 2006 (Semple, 2008). De maneira similar, existe uma diáspora peruana composta de exilados e de migrantes econômicos no Chile, que veio a aumentar em consequência de uma situação de fechamento de espaços políticos e de crise econômica no Peru. Especificamente, isso foi resultado de processos que amadureceram durante a década de 1980, expressando-se nos primeiros anos da década seguinte: a hiperinflação e a dívida externa de 1980 a 1992, a guerra civil do estado peruano contra o Sendero Luminoso e o Movimento Revolucionário Túpac Amaru, entre 1980 e 1996, e o golpe de estado de Fujimori em abril de 1992 (Luque Brazán, 2009). 
Tudo isso sugere a importância de uma análise futura a respeito da relação entre democracia e exílio, bem como estudos sobre a complexa e constantemente ambígua relação entre exílio e migração econômica.

(Recebido para publicação em junho de 2009)

(Versão definitiva em janeiro de 2010)

\section{NOTAS}

1. Em 1829, Hendrik Provó Kluit, em De deditione profugorum, afirmou o direito de asilo político ao excluir dos tratados de extradição as pessoas perseguidas politicamente.

2. Anos mais tarde, Peru e Colômbia seguiriam enfrentando as ações de guerrilhas, como o Sendero Luminoso ou as Farc (Forças Armadas Revolucionárias da Colômbia), e o ELN (Exército de Libertação Nacional). O complexo do narcotráfico, a delinquência, a guerrilha, a contrainsurgência e os paramilitares seguiriam acossando a sociedade colombiana, enquanto, na tensa situação em Chiapas e nos Andes, durante as décadas de 1990 e 2000, seriam evitados os efeitos colaterais da violência no âmbito de um contexto internacional cambiante.

3. A análise dos exilados no Caribe e na América Central se baseia sobretudo em Ameringer (1974, especialmente pp. 161-221; 1996).

4. Para o caso dos exilados brasileiros, ver Rollemberg (1999); Viz Quadrat (2004); e Prestes Massena (2009).

5. Ver Green (2009). 


\section{REFERÊNCIAS BIBLIOGRÁFICAS}

ACNUR (Alto Comissariado das Nações Unidas para Refugiados). (1951), “Convención sobre el Estatuto de los Refugiados". Disponível em http:/ / www.acnur.org/biblioteca/pdf/0005.pdf. Acessado em 18 de maio de 2009.

AMERINGER, Charles D. (1974), The Democratic Left in Exile: The Antidictatorial Struggle in the Caribbean, 1945-1959. Coral Gables, University of Miami Press.

. (1996), The Caribbean Legion: Patriots, Politicians, Soldiers of Fortune, 1946-1950. University Park, PA, Pennsylvania State University Press.

BARAHONA, Marvin. (2005), Honduras en el Siglo XX: Una Síntesis Histórica. Tegucigalpa, Guaymuras.

BONILlA, Emma. (1989), Continuismo y Dictadura. Tegucigalpa, Litográfica Comayagüela.

CENTENO, Miguel Angel. (1999), “War in Latin America: The Peaceful Continent?", in J. Lopez-Arias e G. Varona-Lacey (eds.). Latin America. An Interdisciplinary Approach. New York, Peter Lang, pp. 121-136.

DESCALZI, Ricardo. (1978), La Real Audiencia de Quito. Claustro en los Andes. Barcelona, Seix Barral.

ESPONDA FERNÁNDEZ, Jaime. (2007), “La Tradición Latinoamericana de Asilo y la Protección Internacional de los Refugiados". Disponível em http://www.acnur. org/biblioteca.pdf/3392.pdf. Acessado em 10 de julho de 2007.

FRANCO, Leonardo et alii. (2001), “Investigación: El Asilo y la Protección de los Refugiados en América Latina. Acerca de la Confusión Terminológica 'Asilo-Refugio'. Informe de Progreso". Disponível em http:/ / www.acnur.org/biblioteca/pdf/0269.pdf. Acessado em 25 de julho de 2008.

GREEN, James N. (2003), "Clerics, Exiles, and Academics: Opposition to the Brazilian Military Dictatorship in the United States, 1969-1974". Latin American Politics and Society, vol. 45, no 1, pp. 87-117.

. (2009), Apesar de Vocês: A Oposição à Ditadura Militar nos EUA, 1964-85. São Paulo, Companhia das Letras.

HALPERÍN DONGHI, Túlio. (1980), Proyecto y Construcción de una Nación. Caracas, Biblioteca Ayacucho.

HERZOG, Tamar. (1995), La Administración como un Fenómeno Social. La Justicia Penal de la Ciudad de Quito (1650-1750). Madrid, Centro de Estudios Constitucionales.

HIRSCHMAN, Albert O. (1970), Exit, Voice, and Loyalty: Responses to Decline in Firms, Organizations, and States. Cambridge, Harvard University Press.

INTERNATIONAL COURT OF JUSTICE. (1951), “Haya de la Torre Case”. Disponível em http://www.icj-cij.org/icjwww/idecisions/isummaries/ihayasummary 510613. htm. Acessado em 25 de julho de 2008.

INTERNATIONAL DEVELOPMENT RESEARCH CENTER. (2008), “Chilean Investigative Journalist Alejandra Matus". Disponível em http:/ / www.edrc.ca. Acessado em 10 de junho de 2008. 
JOHNSON, John J. (1992) [1951], "Foreign Factors", in H. M. Hamill (comp.), Caudillos: Dictators in Spanish America. Norman/London, University of Oklahoma Press.

KACOWICZ, Arie M. (2005), The Impact of Norms in International Society. Notre Dame, University of Notre Dame Press.

KAPLAN, Marion A. (2008), Dominican Haven. New York, Museum of Jewish Heritage.

KATRA, William H. (1996), The Argentine Generation of 1837. London, Associated University Presses.

LIBERTAD DE PRENSA. (2006), “La Interminable Batalla Legal de Alejandra Matus”. Disponível em http:/ / www.libertad-prensa.org. Acessado em 25 de maio de 2006.

LOVEMAN, Brian. (1993), The Constitution of Tyranny. Pittsburgh, University of Pennsylvania Press.

e LIRA, Elizabeth. (1999), Las Suaves Cenizas del Olvido. Vía Chilena de Reconciliación Política, 1814-1932. Santiago, LOM.

LUNA, David Alejandro. (1962), El Asilo Político. San Salvador, Editorial Universitaria.

LUNA, Félix. (1995), Historia General de la Argentina. Buenos Aires, Planeta, vol. 5.

LUQUE BRAZÁN, José Carlos. (2009), “Los Refugiados Peruanos y sus Asociaciones Políticas en Santiago de Chile (1990-2006)". Estudios Interdisciplinarios de América Latina y el Caribe, vol. 20, no 1, pp. 93-116.

LYNCH, John. (1989), "The Origins of Spanish American Independence", in L. Bethell (ed.), The Independence of Latin America. Cambridge, Cambridge University Press, pp. $1-48$.

PRESTES MASSENA, Andreia. (2009), “Entre Brasil e Moçambique: Os Caminhos Percorridos no Exílio". Estudios Interdisciplinarios de América Latina y el Caribe, vol. 20, no 1, pp. 61-92.

RODRÍGUEZ PLATA, Horacio. (1976), Santander en el Exilio. Bogotá, Editorial Kelly.

ROLLEMBERG, Denise. (1999), Entre Raízes e Radares. Rio de Janeiro, Record.

RONIGER, Luis e GREEN, James. (2007), "Exile and the Politics of Exclusion in Latin America". Latin American Perspectives, vol. 34, no 4, pp. 3-6.

RONIGER, Luis e SZNAJDER, Mario. (2004), O Legado de Violações dos Direitos Humanos no Cone Sul. São Paulo, Perspectiva.

. (2008), “Antecedentes Coloniales del Exilio Político y su Proyección en el Siglo XIX". Estudios Interdisciplinarios de América Latina y el Caribe, vol. 18, no 2, pp. 31-51.

SAN CRISTÓVAL, Evaristo. (1941), El Gran Mariscal Luis José de Orbegoso. Lima, Gil S.A. Editores.

SCARDAVILLE, Michael C. (1977), Crime and the Urban Poor. Mexico City in the Late Colonial Period. London, University Microfilms International.

SEMPLE, Kirk. (2008), "Rise of Chavez Sends Venezuelans to Florida". The New York Times, 23 de janeiro. Disponível em http://www.miami.edu. Acessado em 12 de junho de 2008. 


\section{Luis Roniger}

SZNAJDER, Mario e RONIGER, Luis. (2007), "Political Exile in Latin America". Latin American Perspectives, vol. 34, no 4, pp. 7-30.

. (2009), The Politics of Exile in Latin America. New York, Cambridge University Press.

VIZ QUADRAT, Samantha. (2004), "Muito Além das Fronteiras", in D. A. Reis, M. Ridenti e R. P. Sá Motta (orgs.), O Golpe e a Ditadura Militar: Quarenta Anos Depois (1964-2004). Bauru, SP, Edusc.

YANKELEVICH, Pablo (comp.). (2002), México, País Refugio. La Experiencia de los Exilios en el Siglo XX. México, Inah/Plaza y Valdés.

YUNDT, Keith W. (1988), Latin American States and Political Refugees. New York, Praeger.

ZUÑIGA, Ángel Huete. (1982), Morazán. Tegucigalpa, Editorial Universitaria. 


\section{ABSTRACT \\ Mass Exile and Political Inclusion and Exclusion in $20^{\text {th }}$ Century}

Due to the strategies implemented by post-Independence Ibero-American states to curtail political participation, exile was mainly reserved as a privilege for ostracized members of the elite, who drew on their support networks in the process. The late $19^{\text {th }}$ and early $20^{\text {th }}$ centuries witnessed a process of "mass exile", expressed by a growing number of exiles from different social classes, excluded due to their participation in politics and public spheres. The expansion of institutional exclusion spawned solidarity networks and increasing attention by the international community towards politics in the exiles' home countries. Old domestic political issues found a transnational echo, based on a growing concern over human rights violations and political persecution. This process produced a radical transformation in the structure, impact, and functioning of political exile from Ibero-American countries.

Key words: exile; institutional exclusion; political participation; international community

\section{RÉSUMÉ}

Exils Massifs, Inclusion et Exclusion Politique au XX $X^{e}$ Siècle

Les stratégies de restriction de la participation politique adoptées par les états ibéro-américains lors de leur indépendance ont fait que l'exil était utilisé comme un privilège réservé surtout à des gens de l'élite ayant subi

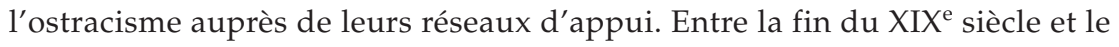
début $\mathrm{du} X X^{\mathrm{e}}$, a eu lieu un processus de "massification" de l'exil atteignant un nombre croissant d'individus de classes sociales variées, conséquence de leur participation à la politique et à la sphère publique. Leur exclusion croissante des institutions a amené l'apparition de réseaux de solidarité et attiré l'attention de la sphère publique internationale sur les politiques des états d'origine. De vieux thèmes de politique interne ont rencontré un écho transnational et pris appui sur un souci grandissant concernant les ateintes aux droits de l'homme et les persécutions politiques. Ces mécanismes ont provoqué une transformation radicale de la structure, de l'impact et de la fonction de l'exil politique chez les états ibéroaméricains.

Mots-clé: exil; exclusion institutionnelle; participation politique; sphère publique internationale 